\title{
Evaluating the Structural Integrity of Fibreglass for the Manufacture of Headgears
}

\author{
Olusegun A. Adefuye, Nurudeen A. Raji, Rafiu O. Kuku, Timothy Oyetade, \\ Ridwan 0. Ola-Gbadamosi
}

Mechanical Engineering Department, Lagos State University, Lagos, Nigeria

Email: nurudeen.raji@lasu.edu.ng

How to cite this paper: Adefuye, O.A., Raji, N.A., Kuku, R.O., Oyetade, T. and Ola-Gbadamosi, R.O. (2021) Evaluating the Structural Integrity of Fibreglass for the Manufacture of Headgears. Modern Mechanical Engineering, 11, 13-26.

https://doi.org/10.4236/mme.2021.112002

Received: March 25, 2021

Accepted: May 23, 2021

Published: May 26, 2021

Copyright () 2021 by author(s) and Scientific Research Publishing Inc. This work is licensed under the Creative Commons Attribution International License (CC BY 4.0).

http://creativecommons.org/licenses/by/4.0/

\begin{abstract}
A composite material is made up of two phases, the matrix, and the reinforcing materials. The reinforcing material is embedded over matrix material. The reinforcing material works to make the matrix material harder. A fibreglass reinforced composite was developed using E-glass fibre reinforcement and epoxy resin matrix. The composites were produced using the hand lay-up technique with varying fibre percentage of $9 \%, 13 \%$ and $25 \%$ by weight percentage of fibreglass mat at orientations of $0^{\circ}, 15^{\circ}, 45^{\circ}$, and $90^{\circ}$ chosen at random. A $13 \%$ by weight percentage of chopped mat was also developed for purpose of comparison. The fabricated composites were subjected to tensile test, flexural test, impact test, punch shear test and hardness test to ascertain the appropriate fibre contents and orientation that is optimum for the manufacture of headgears. Analysis of Variance was carried out to determine level of significance and percentage contribution of the parameters. The results show that both fibre orientation and percentage of fibre content reinforcement of have significant influence on the strength and fracture energy of the composite .The fibre orientation has a higher impact on the strength of the composite $(79.74 \%)$ while the percentage of fibre reinforcement has a lesser impact on the tensile strength of the composite (20.26\%). However, the fibre orientation has a lesser impact on the fracture energy of the composite (24.54\%) while the percentage of fibre reinforcement has a higher impact on the fracture energy of the composite (75.46\%) The result from this study shows that the increase in fibre content increases flexural strength and impact toughness of the fibreglass reinforced composite. A fibre orientation of $90^{\circ}$ and fibre reinforcement of $25 \% \mathrm{wt}$. was determined to be optimally suitable for the manufacture of headgears.
\end{abstract}

\section{Keywords}

Headgears, Fibre Glass, Fibre Orientation, Polymer Composites 


\section{Introduction}

Over the years, protective head gear manufacturers have employed different materials in the production of cheap strong and effective head gears. This ranged from the use of steel, leather, aluminium, plastic, and Bakelite before fibre glass headgear production proved to be a worthy technology.

Fibreglass materials are of economic importance and its products are beneficial to safety engineering applications. Fibreglass generates rising, essential, and cost-effective products widely beneficial to the industrial spectrum either as one of many types of strengthening, as a fabrics or other products for acoustics, electrical, and thermal insulation, or more lately for fast insulation. Fortunately, in nearly unlimited supply, the raw materials are easily and economically acquired from commonly accessible inorganic indigenous ores. A large proportion of the world's fibre glass is used to strengthen plastics [1]. The types of fibreglass along with their various commercial products have wide applications, Fibreglass types can be differentiated by their various chemical compositions, physical properties, and the varying ASTM standards for each of the types [2]. The most common reinforcing material in the marine application (construction of ships, yacht and ferries) is still E-glass fibre, which has a good maximum tensile strength, about $2200 \mathrm{MPa}$, and an ultimate tensile strain of about $2.5 \%$ combined with outstanding resistance to moisture and chemical aggression. E-glass, due to its chemical composition has excellent electrical insulation properties. Glass fibres with high-strength glass are generally known as S-glass in the United States and $\mathrm{R}$-glass in Europe. $\mathrm{S}$ glass has a higher content of $\mathrm{SiO}_{2}, \mathrm{Al}_{2} \mathrm{O}_{3}$, and $\mathrm{MgO}$ than E-glass. Both the E-glass and the S-glass lose up to half their tensile strength when the temperature increases from the $70^{\circ} \mathrm{F}$ (room temperature) to $1000^{\circ} \mathrm{F}$ (approx. $540^{\circ} \mathrm{C}$ ), even if both fibre types still preserve a good resistance to corrosion [3] [4] [5].

Fibre-reinforced polymer composites can provide a much better strength-toweight ratio than metals, sometime by $15 \%$. The lower weight results in lower fuel consumption and emissions, enhanced aerodynamic efficiency, lower manufacturing costs. The aviation industry was the first attracted to such benefits and it was the manufacturers of military aircrafts who initially seized the opportunity to use composites characteristics to improve the speed and flexibility of their products. E-Glass fibres are majorly deployed in small passenger aircraft parts, radomes, and rocket motor casings while S-Glass are deployed in regions with high loadings because of its high specific strength, fatigue and corrosion resistance. Generally, fibre composites have a few drawbacks: some of the corresponding laminates display weak interfaces adhesion, yielding in poor resistance to out-of-plane tensile loads; susceptibility to impact-damage and strong possibility of some internal damages evolving unnoticed; moisture absorption and consequent degradation; occurrence of possible manufacturing defects [6].

Weight improvements and impact performance of air craft parts without compromising relevant properties have been studied, Qin et al., (2018) [7] developed 
glassfibre reinforced polymers (GFRP) incorporating ferromagnetic microwires to improve the impact performance. Based on both the absorption and impact behavior, the study proposed a design of the microwire/GFRP composites to achieve best possible absorption and impact performance desirable for aeronautical structures and wind turbines.

In this study we will consider the mechanical and structural qualities of fibreglass and determine it suitability to produce head gears and possibly consider its eligibility for mass production. Fibreglass is light in weight, very durable and very powerful. Compared to metal, its bulk strength, stiffness and weight, hardness, transparency, chemical attack resistance, stability, and inertness, as well as desirable fibre characteristics such as strength, flexibility and stiffness are also very beneficial compared to metals [8]. The best part of fibreglass is its ability to get moulded into various complex shapes, used widely for the manufacture of structural composites, printed circuit boards and a wide range of special-purpose products (bathtubs, boats, aircraft, roofing, and other applications [9].

Studies had been carried out to investigate the necessary criteria for the successful manufacture of headgears. The tensile dynamic behaviour of a quasi-unidirectional E-glass/polyester composite was investigated for a non-unidirectional material composed of $5 \%$ fibre volume ratio of weft fibres. The weft fibres of 5\% fibre volume ratio observed greater Young's modulus and improved the failure stress (40 MPa) [10]. The compressive and impact behaviour of discontinuous glass fibre reinforced epoxy composites with addition of fillers was investigated by Gupta et al. [11]. The result showed fly ash particles led to reduced compressive and impact strength of the composites compared to the calcium carbonate filler in the composites. The aspect ratio of the fibre increased the compressive strength and decreased the impact strength.

There is need to understand the head anatomy, anthropometry, biomechanics, fits, materials, manufacturing, and testing standards for headgears manufacture. Mamalis et al. (1996) [12] investigated the crashworthiness of the square frusta fibreglass composite material. The fibreglass was subjected to axial compression at various strain rate and the effect of the specimen geometry and the loading rate on the energy absorbing capacity of the fibreglass was experimentally documented. The mechanics of the axial crumbling process from macroscopic and microscopic points of view were also investigated theoretically and experimentally. The collapse modes at macroscopic and microscopic scale during the failure process were observed and analysed. The results showed theoretical models are also efficient in predicting the energy absorbing capacity of a collapsed shell.

Several tests had been developed for assessment of protective headgears. Hajiaghamemar et al., (2015) [13] investigated the potential use of impact test procedure. The study represented the preliminary assessment of the test apparatus for use in development of protective headgear designed to prevent injury due falls considering linear, angular acceleration and collision velocity at impact conditions. Adekomaya et al., (2017) [14] analyzed the effect of fibre loading and orientation on the tensile and impact strength of the polymeric composite mate- 
rials. Series of experimental works were done to demonstrate the manufacturing of glass-fibre reinforced epoxy resin with special attention on the influence of oriented reinforced composite material. A significant improvement was discovered in the mechanical properties of oriented reinforced composite materials due to changes noticed in the impact strength.

The development of the fibreglass had been studied using different techniques by Wallenberger et al., (2010) [15] and El-Wazery et al., (2017) [16]. Series of experiments were conducted to demonstrate the manufacturing of glass-fibre reinforced epoxy resin with special attention on the influence of oriented reinforced composite material. El-Wazery et al., 2017 [16] developed a E-glass fibre with random oriented reinforced polymer composite by hand lay-up technique with varying fibre percentages (15\%, $30 \%, 45 \%$, and $60 \%$ by weight percentage). The best mechanical properties obtained at $60 \mathrm{wt} \%$ of glass fibre of fabricated composites show good comparison to the standard requirement for the use of fibreglass in headgear production [17]. The various mechanical properties except the impact strength were improved with increase in fibre glass volume and that an important characteristic of fibreglass-polyester composite is high toughness. Also, significant improvement was observed in the mechanical properties for oriented reinforced composite subjected to dynamic form of loading [14].

Kumar et al., (2014) [18], constructed a fibreglass headgear using the fibreglass hand lay-up operation. They laid Emphasis on constructing the headgear with superior structural strength and stability over the polyethylene thermoplastic while also ensuring that the weight is kept as low as possible comparison with the polyethylene plastic headgear and ensuring that the product is economical. The fibreglass cloth was chosen keeping in mind various parameters concerning the weight and cost of the fibreglass reinforced glass headgear and ensuring that the mechanical properties were not compromised. Four layered glass specimens were tested for tensile strength, hardness and flexural strength and have been compared alongside the standard mechanical properties of a High-density polyethylene (HDPE) Industrial headgear. While the Fibreglass reinforced plastic (FRP) emerged as a clear winner over the HDPE Industrial headgear with respect to the structural properties, the study discussed the areas of research and need for improvement in design and in its economy.

\section{Materials and Methods}

\subsection{Materials}

\subsubsection{Preparation of the Specimen}

The fibreglass composite prepared contained epoxy resin matrix and E-glass variant reinforcement. The choice of the epoxy resin relies on its high chemical and solvent resistance, high Strength and good flexural strength, low cost and low toxicity, excellent adhesion to various substrates, low shrinkage, effective electrical insulation. The tensile strength of the resin ranges from $90-120 \mathrm{MPa}$ and its modulus ranges from $3100-3800 \mathrm{MPa}$. The glass transition temperature range is from $150^{\circ} \mathrm{C}-220^{\circ} \mathrm{C}$. It has a bonding strength of about $2000 \mathrm{psi}$. 


\subsubsection{Test Equipment's}

The mechanical tests were done on the specimen using the Universal Instron Machine, model 3369, maker (Instron), Monsanto Testing Machine for hardness and shearing and the Izod impact test machine.

\subsection{Methods}

\subsubsection{Specimen Preparation}

Three different combinations of composite specimen were prepared and cured at room temperature as tabulated in Table 1 using the hand-layup technique. The specimens were produced according to the ASTM standard, $200 \times 30 \mathrm{sq} \cdot \mathrm{mm}$.

\subsubsection{Hand Layup Technique}

The moulds were prepared with the required dimension for the specimen using glass and plywood with smooth surface finish as shown in Figure 1. Release gel was sprayed on the mould surface to prevent sticking of the polymer matrix to the mould surface. Thin plastic (Perspex) sheets were used at the top and bottom of the mould plate to get a good surface finish for the product. The reinforcement was prepared in form of chopped strand mats (Figure 2) to fit in the mould and the epoxy resin in liquid form is mixed in suitable proportion with the curing agent at ratio 2:1. The mixture was spread in the mould and the process repeated for each layer of polymer and mat.

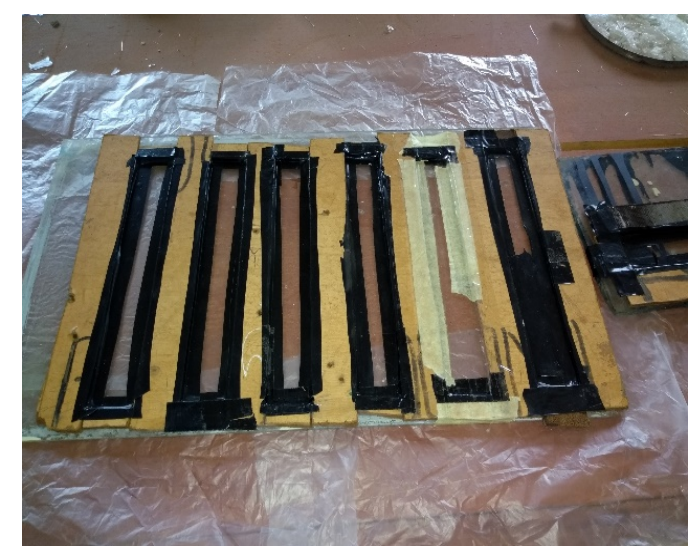

Figure 1. Specimen of mould.

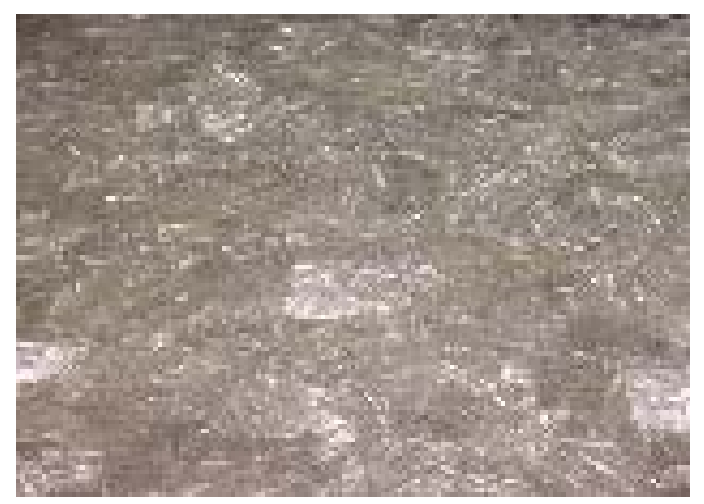

Figure 2. Chopped mat of fiberglass. 
Table 1. Specimen composition.

\begin{tabular}{lc}
\hline Composition and fibre orientation in the composite & Designation \\
\hline $9 \%$ wt fibre enhancement at $0^{\circ}$ orientation & $\mathrm{C}_{11}$ \\
$9 \% \mathrm{wt}$ fibre enhancement at $15^{\circ}$ orientation & $\mathrm{C}_{12}$ \\
$9 \% \mathrm{wt}$ fibre enhancement at $45^{\circ}$ orientation & $\mathrm{C}_{13}$ \\
$9 \% \mathrm{wt}$ fibre enhancement at $90^{\circ}$ orientation & $\mathrm{C}_{14}$ \\
$13 \% \mathrm{wt}$ fibre enhancement at $0^{\circ}$ orientation & $\mathrm{C}_{21}$ \\
$13 \% \mathrm{wt}$ fibre enhancement at $15^{\circ}$ orientation & $\mathrm{C}_{22}$ \\
$13 \% \mathrm{wt}$ fibre enhancement at $45^{\circ}$ orientation & $\mathrm{C}_{23}$ \\
$13 \% \mathrm{wt}$ fibre enhancement at $90^{\circ}$ orientation & $\mathrm{C}_{24}$ \\
$25 \% \mathrm{wt}$ fibre enhancement at $0^{\circ}$ orientation & $\mathrm{C}_{31}$ \\
$25 \% \mathrm{wt}$ fibre enhancement at $15^{\circ}$ orientation & $\mathrm{C}_{32}$ \\
$25 \% \mathrm{wt}$ fibre enhancement at $45^{\circ}$ orientation & $\mathrm{C}_{33}$ \\
$25 \% \mathrm{wt}$ fibre enhancement at $90^{\circ}$ orientation & $\mathrm{C}_{34}$ \\
\hline $13 \%$ wt chopped mat fibre enhancement at random orientation & $\mathrm{C}_{90}$ \\
\hline
\end{tabular}

\subsubsection{Mechanical Test}

The tensile strength test, punch shear test, impact test, flexural test and hardness test were conducted on the specimens. The tensile properties were obtained using the universal Instron machine. The ability of the composite to absorb shock and energy when subjected to dynamic loading was investigated using the impact test.

The resistance of the composite to plastic deformation resulting from indentation, abrasion and scratching and the stiffness of the fibreglass was investigated using the hardness test procedure. Also, the punching shear was designed to apply stress to the specimens for investigating the sliding failure of the material.

The flexural test exposes the flexural strength of the composite material specimens fabricated and it was carried out by using universal testing machine at $1000 \mathrm{kN}$ full scale load capacity with a cross head speed of $5 \mathrm{~mm} / \mathrm{min}$ according to ASTM standard D-790 $(65 \mathrm{~mm} \times 31.21 \mathrm{~mm})$, thickness is $5.2 \mathrm{~mm}$. Flexural strength of the composite's material was then obtained from the Equation (1).

$$
\sigma_{f}=\frac{3 F L}{2 w t^{2}}
$$

where $F$ is the applied load $(\mathrm{N}), L$ is support span $(\mathrm{mm}), w$ and $t$ are width and thickness of the specimen $(\mathrm{mm})$, respectively.

\subsubsection{Structural Integrity Test}

The structural integrity measures the effectiveness and efficiency of the fibreglass in terms of its ability to withstand service loads without exceeding its allowable stress and deflection. The composites of epoxy E-glass (wet) and epoxy E-glass (UD) were both subjected to ANSYS software analysis to determine their various total deformation, maximum shear stress, maximum shear elastic strain, maxi- 
mum principal stress, maximum principal elastic strain, equivalent stress, equivalent elastic strain, shear stress, deformation. The test piece was subjected to loading force of $2231.75278 \mathrm{~N}$.

\subsection{Data Analysis Technique}

The randomized completely block design ( $\mathrm{RCBD}$ ) is probably the most frequent used technique. The fundamental idea of the RCBD is to group experimental material together into homogeneous blocks. The object of this grouping is to keep the errors within each group as small as possible [19]. The randomized complete block design is chosen for the following advantages:

1) Using blocks of more homogeneous experimental material usually results in more accurate results than if a completely randomized design is used.

2) Any number of treatments and any number of replicates (blocks) can be used. Whereas, In the complete block design, every treatment will have the same number of replicates.

The model for the Complete Randomized Block Design is defined as:

$$
y_{i j}=\mu+\tau_{i}+\beta_{j}+\varepsilon_{i j}
$$

where

$y_{i j}$ is the random variable representing the response for treatment $i$ observed in block $j$.

$\mu$ is a constant (which may be thought of as the overall mean)

$\tau_{i}$ is the additive effect of the $i^{\text {th }}$ treatment $(i=1,2,3, \cdots, k)$

$\mathcal{E}_{i j}$ is the random error for the $I^{\text {th }}$ treatment in the $f^{\text {th }}$ block.

SS denotes Sum of Squares, MS denotes Mean of Squares, df denotes degree of freedom,

The blocks are the respective fibre enhancement percentage represented below

Block $1=9 \%$, Block $2=13 \%$, Block $3=25 \%$

The treatments are the respective fibre orientation represented below

Treatment $1=0^{\circ}$ Fibre orientation, Treatment $2=15^{\circ}$ Fibre Orientation

Treatment $3=45^{\circ}$ Fibre Orientation Treatment $4=90^{\circ}$ Fibre Orientation

The yield are the respective outputs for each experiment i.e. (tensile strength, strain, flexural strength).

\section{Results and Discussions}

\subsection{Tensile Properties}

The mechanical test exposes the yield strength, ultimate tensile strength, and fracture strength of the material. The maximum tensile stress sustained by each of the variant fibreglass is as shown in Figure 3 and Table 2. For 9\% fibre reinforcement, a tensile strength of $40.5773 \mathrm{Mpa}$ is recorded and it increased to 40.5981 Mpa, 47.0023 Mpa and 48.9894 Mpa as the fibre orientation is increased to $15^{\circ}, 45^{\circ}$ and $90^{\circ}$ respectively. The same trend is observed for subsequent levels of fibre reinforcement (13\% and $25 \%)$ as it is observed that the increase in fibre orientation provides gives rise to increment in tensile strength of the 


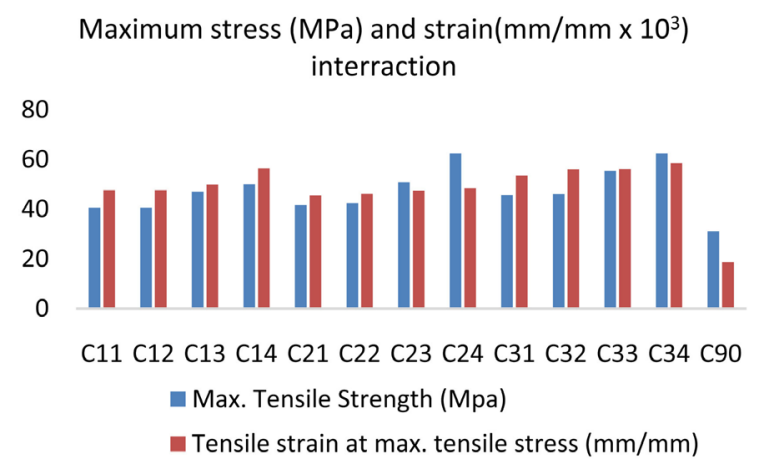

Figure 3. Maximum stress-strain evaluation for fibreglass reinforce composite.

Table 2. The tensile strength of varieties of fibre reinforcement with different fibre orientation.

\begin{tabular}{ccccc}
\hline \multirow{2}{*}{ Block (fibre enhancement) } & \multicolumn{4}{c}{ Treatment (Fibre orientation) } \\
\cline { 2 - 5 } & 1 & 2 & 3 & 4 \\
\hline 1 & 40.5773 & 40.5981 & 47.0023 & 48.9894 \\
2 & 41.5543 & 42.3216 & 50.7849 & 62.2472 \\
3 & 45.5616 & 45.9989 & 55.3298 & 58.4000 \\
\hline
\end{tabular}

composite. For same fibre orientation of $0^{\circ}, 15^{\circ}$ and $45^{\circ}$, an increase in in fibre reinforcement up to $25 \%$ increases the tensile strength. However, there is an exception for $90^{\circ}$ fibre orientation as the strength increases to $62.2472 \mathrm{Mpa}$ at $13 \%$ fibre reinforcement while a lesser strength is recorded at $25 \%$ fibre reinforcement.

Table 3 shows the two-factor Analysis of variance for the strength recorded which was dependent on the percentage fibre-reinforcement and fibre orientation. It is shown that both fibre orientation and percentage fibre reinforcement have significant influence on the strength of the composite at level of significance $\alpha=0.05$ as the F-value of 15.557 and 5.929 exceeds the critical $F$ value (Fcrit) of 4.757 and 5.143 for fibre orientation and percentage fibre reinforcement respectively. The percentage contribution of fibre orientation and fibre reinforcement to the tensile strength of the composite is 79.74 and 20.26 respectively, this implies fibre orientation is the most significant parameter as the composite is typically an anisotropic material which is greatly dependent on the orientation of fibre.

The relative comparison is a measure of the material deformation relative to the maximum stress. The relative comparison of the composites as shown in Figure 4 reveals that the $13 \%$ wt chopped mat fibre enhancement at random orientation (C90) has the highest performance relative value of 1.66 followed by the $13 \%$ wt fibre enhancement at $90^{\circ}$ orientation $(\mathrm{C} 24)$ with relative value of 1.29 .

The maximum energy at fracture sustained by each of the variant fibreglass is shown in Figure 5 and Table 4. For 13\% wt. and 25\% wt. fibre reinforcement, as 


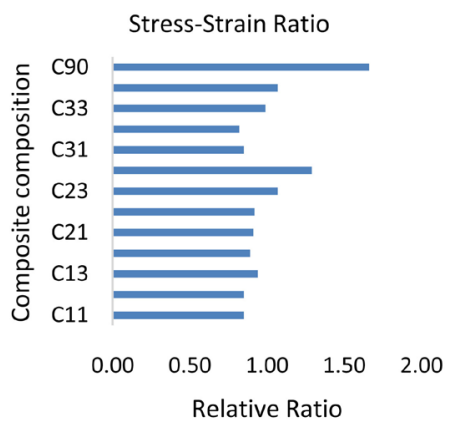

Figure 4. Relative values of composite maximum stress to strain.

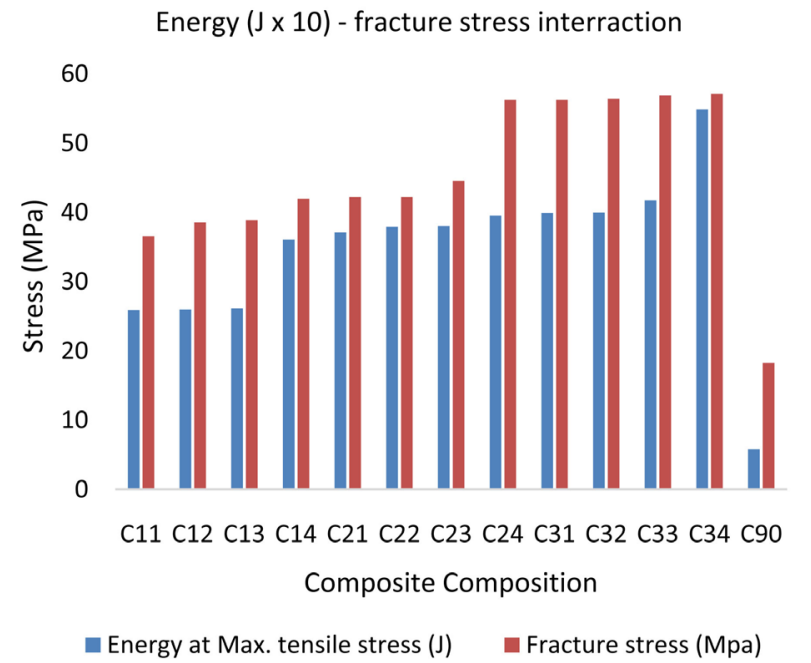

Figure 5. Energy and fracture stress properties of the composite material.

Table 3. Analysis of variance for tensile strength obtained from varieties of fibre reinforcement with different fibre orientation.

\begin{tabular}{cccccccc}
\hline Source of Variation & SS & $\begin{array}{c}\text { Percentage } \\
\text { Contribution }\end{array}$ & df & MS & F & P-value & F crit \\
\hline Fibre Reinforcement & 104.240 & 20.259 & 2.000 & 52.120 & 5.929 & 0.038 & 5.143 \\
Fibre Orientation & 410.295 & 79.741 & 3.000 & 136.765 & 15.557 & 0.003 & 4.757 \\
Error & 52.746 & & 6.000 & 8.791 & & & \\
& & & & & & & \\
Total & 567.281 & 100 & 11.000 & & & & \\
\hline
\end{tabular}

Table 4. The fracture energy of varieties of fibre reinforcement with different fibre orientation.

\begin{tabular}{ccccc}
\hline \multirow{2}{*}{ Block (fibre enhancement) } & \multicolumn{4}{c}{ Treatment (Fibre orientation) } \\
\cline { 2 - 5 } & 1 & 2 & 3 & 4 \\
\hline 1 & 25.9120 & 25.9960 & 25.1150 & 36.0010 \\
2 & 37.1111 & 37.9040 & 38.0000 & 39.5303 \\
3 & 39.9240 & 39.9670 & 41.7630 & 54.8800 \\
\hline
\end{tabular}


the fibre orientation is increased to $15^{\circ}, 45^{\circ}$ and $90^{\circ}$ the energy absorbed before fracture increases. However, there is an exception for the $9 \% \mathrm{wt}$. fibre reinforcement as the energy increases from $0^{\circ}$ to $15^{\circ}$ fibre orientation while it decreases from $15^{\circ}$ to $45^{\circ}$ fibre orientation. Table 5 shows the two-factor Analysis of variance for the fracture energy recorded which was dependent on the percentage fibre-reinforcement and fibre orientation.

It is shown that both fibre orientation and percentage fibre reinforcement have significant influence on the strength of the composite at level of significance $\alpha=$ 0.05 as the F-value of 5.559 and 24.358 exceeds the critical F value (Fcrit) of 4.757 and 5.143 for fibre orientation and percentage fibre reinforcement respectively. The percentage contribution of fibre orientation and fibre reinforcement to the tensile strength of the composite is 25.54 and 74.46 respectively, this implies the percentage of fibre is a more significant parameter on the fracture energy of the composite.

The test reveals that the $25 \%$ wt fibre enhancement at $90^{\circ}$ orientation (C34) has the maximum energy compared to others but also undergoes the highest form of deformation as seen in Figure 6 shows the absorbed energy of the composites. The relative stress-strain value for $\mathrm{C} 34$ is 1.07 and of same value with C23 as shown on Figure 4, however energy absorbed by C23 (13\% fibre reinforcement at $45^{\circ}$ orientation) is lower. The C24, C31, C32, C33, and C34 composite were observed to have the highest range of Moduli indicating elasticity

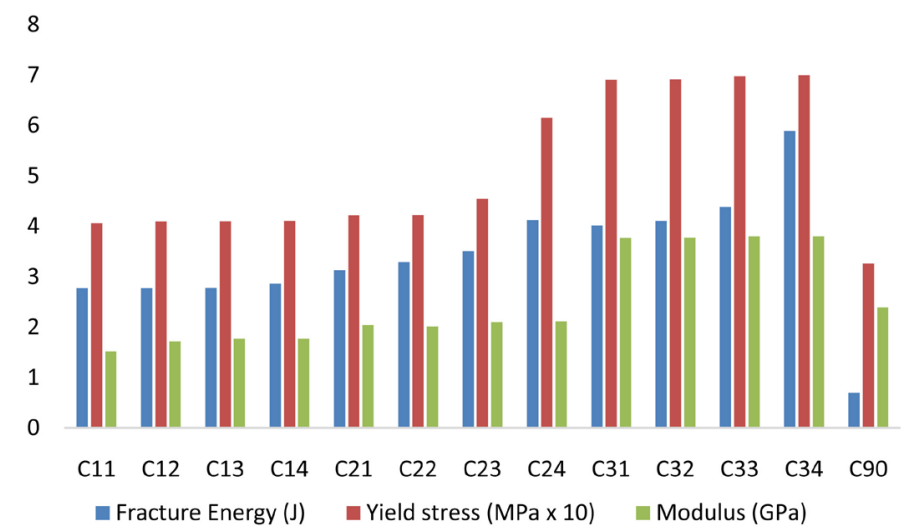

Figure 6. Absorbed energy and failure chart for fibreglass reinforced composite.

Table 5. Analysis of variance for Fracture energy recorded from varieties of fibre reinforcement with different fibre orientation.

\begin{tabular}{cccccccc}
\hline Source of Variation & SS & $\begin{array}{c}\text { Percentage } \\
\text { Contribution }\end{array}$ & df & MS & F & P-value & F crit \\
\hline Fibre Reinforcement & 514.243 & $\mathbf{7 4 . 4 6 2}$ & 2.000 & 257.121 & 24.358 & 0.001 & 5.143 \\
Fibre Orientation & 176.369 & $\mathbf{2 5 . 5 3 8}$ & 3.000 & 58.790 & 5.569 & 0.036 & 4.757 \\
Error & 63.337 & & 6.000 & 10.556 & & & \\
& & & & & & & \\
Total & 753.949 & 100 & 11.000 & & & & \\
\hline
\end{tabular}


characteristics of the composites. These range of the composite also have the highest values of yield strength showing their ability to undergo large plastic deformation before fracture.

\subsection{Flexural Properties}

The related properties to the flexural rigidity of the fibreglass composite is as expressed in Figure 7. The analysis shows that the flexural strength of the composite increases with increasing percentage content of the fibre. The influence of the fibre orientation is more pronounce in the $13 \%$ fibre content composite $\left(\mathrm{C}_{21}\right.$ - $\mathrm{C}_{24}$ ). At a higher fibre content, the influence of the orientation of the fibres within the composite content is lesser as exposed in composite compositions $\mathrm{C}_{31}$ - $\mathrm{C}_{34}$ ). A sustainable composite fabrication between $\mathrm{C}_{24}$ and $\mathrm{C}_{34}$ is favoured from this study for the manufacture of the headgear.

\subsection{Impact Toughness}

The variation of impact Toughness with the glass fibre content of glass fibre reinforced polymer composites is as shown in Table 6. The impact resistance of the composite improves with the content of the fibre reinforcement. The impact resistance is considered low due to resins brittle nature. However, results showed that reinforcing it with glass fibres improves the impact resistance.

\subsection{Selection Criteria for Headgears}

Table 7 shows the ranking of the composite based on desireable mechanical properties for headgear manufacture. A rank of 1 shows the composite has the most suitable property while a rank of 12 indicates the composite has the least suitable property. It is seen that C34 (25\% wt. fibre reinforcement at $90^{\circ}$ fibre

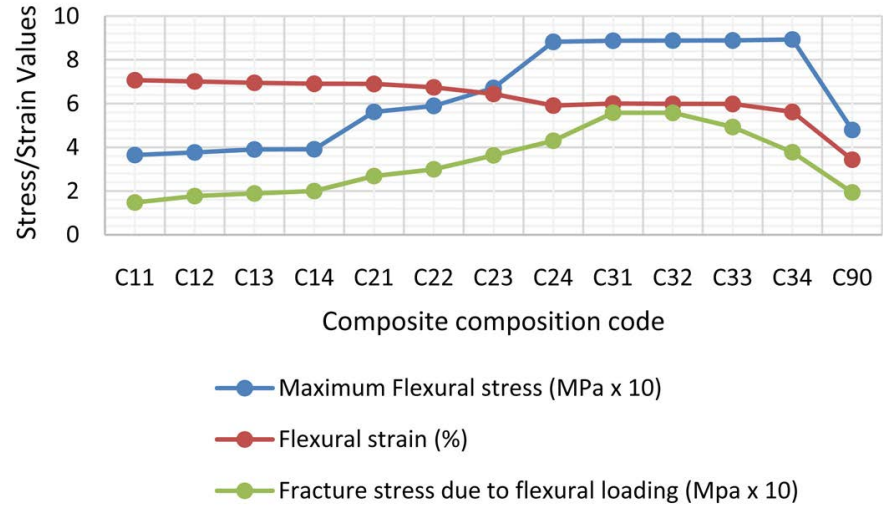

Figure 7. Flexural rigidity analysis chart.

Table 6. Variation of impact Toughness with the glass fibre content of glass fibre reinforced polymer composites

\begin{tabular}{cccccccccccccc}
\hline Designation & $\mathrm{C}_{11}$ & $\mathrm{C}_{12}$ & $\mathrm{C}_{13}$ & $\mathrm{C}_{14}$ & $\mathrm{C}_{21}$ & $\mathrm{C}_{22}$ & $\mathrm{C}_{23}$ & $\mathrm{C}_{24}$ & $\mathrm{C}_{31}$ & $\mathrm{C}_{32}$ & $\mathrm{C}_{33}$ & $\mathrm{C}_{34}$ & $\mathrm{C}_{90}$ \\
\hline Impact Toughness (J) & 8.3 & 8.3 & 8.4 & 9.1 & 8.7 & 8.7 & 9.0 & 10 & 9.1 & 9 & 10 & 11 & 9.6
\end{tabular}


Table 7. Ranking of composite based on desireable properties for headgear manufacture.

\begin{tabular}{lcccc}
\hline \multirow{2}{*}{ Composite } & \multicolumn{3}{c}{ Rank } \\
\cline { 2 - 5 } C11 & Tensile Strength & Impact Toughness & Energy at fracture & Flexural Strength \\
\hline C12 & 12 & 11 & 12 & 12 \\
C13 & 11 & 11 & 11 & 11 \\
C14 & 10 & 10 & 10 & 10 \\
C21 & 9 & 4 & 9 & 9 \\
C22 & 8 & 8 & 8 & 8 \\
C23 & 7 & 8 & 7 & 7 \\
C24 & 6 & 6 & 6 & 6 \\
C31 & 1 & 2 & 4 & 5 \\
C32 & 5 & 4 & 5 & 4 \\
C33 & 4 & 6 & 3 & 3 \\
C34 & 3 & 2 & 2 & 2 \\
\hline
\end{tabular}

orientation) possesses the highest impact toughness, Highest Ffracture energy and Highest flexural strength. Hence, it is optimally suitable be used in the fabrication of headgears.

\section{Conclusions}

This study experimentally investigated the structural integrity of fibreglass in a composite that makes it fit for the local manufacture of headgears. The mechanical characteristics of the various composite produced were investigated. The percentage of the fibreglass in the composite and the fibreglass orientation while ensuring that the mechanical properties were not compromised. The investigations were carried out by subjecting the samples to various mechanical tests. The results show that both fibre orientation and percentage of fibre content reinforcement of have significant influence on the strength and fracture energy of the composite. The fibre orientation has a higher impact on the strength of the composite $(79.74 \%)$ while the percentage of fibre reinforcement has a lesser impact on the tensile strength of the composite (20.26\%). However, the fibre orientation has a lesser impact on the fracture energy of the composite (24.54\%) while the percentage of fibre reinforcement has a higher impact on the fracture energy of the composite (75.46\%). The result from this study shows that the increase in fibre content increases flexural strength and impact toughness of the fibreglass reinforced composite.

Successful fabrication of glass fibre with optimal fibre orientation of $90^{\circ}$ and fibre reinforcement of $25 \mathrm{wt} \%$ was achieved and cost effective using simple hand lay-up technique. The resulting composite is found suitable for the manufacture of local headgears with comparable strength and cost performance with standards. 


\section{Conflicts of Interest}

The authors declare no conflicts of interest regarding the publication of this paper.

\section{References}

[1] Gujja, S.K., Sunil, C.H. and Joe, J. (2014) Fabrication of Glass Fibre Helmet. Proceedings of the International Conference on Information, Engineering, Management and Security (ICIEMS), 156-169.

[2] Watson, J.C. and Raghupathi, N. (1987) Glass Fibres. In: Composites, Engineered Materials Handbook, Vol. 1, ASM International, Almere, 107.

[3] Hoge, J. and Leach, C. (2016) Epoxy Resin Infused Boat Hulls. Reinforced Plastics, 60, 221-223. https://doi.org/10.1016/j.repl.2016.01.002

[4] Gargano, A., Pingkarawat, K., Blacklock, M., Pickerd, V. and Mouritz, A.P. (2017) Comparative Assessment of the Explosive Blast Performance of Carbon and Glass Fibre-Polymer Composites Used in Naval Ship Structures. Composite Structures, 171, 306-316. https://doi.org/10.1016/j.compstruct.2017.03.041

[5] Marsh, G. (2003) Material Trends for FRP Boats. Reinforced Plastics, 47, 23-26. https://doi.org/10.1016/S0034-3617(03)00931-7

[6] Qin, F.X., Peng, H.X., Chen, Z., Wang, H., Zhang, J.W. and Hilton, G. (2013) Optimization of Microwire/Glass-Fibre Reinforced Polymer Composites for Wind Turbine Application. Applied Physics A, 113, 537-542. https://doi.org/10.1007/s00339-013-7820-2

[7] Tanasa, F. and Zanoaga, M. (2013) Fibre-Reinforced Polymer Composites as Structural Materials for Aeronautics. Proceedings of the International Conference of Scientific Paper, Brasov, 1-3 June 2013, 23-25.

[8] Wallenberger, F.T. (1999) Structural Silicate and Fibres Processes, Structures, Properties, Applications. Kluwer Academic Publishers, Dordrecht, 129-168. https://doi.org/10.1007/978-1-4419-8722-8 6

[9] Wallenberger, F.T. (1994) Melt Viscosity and Modulus of Bulk Glasses and Fibres: Challenges for the Next Decade. Present State and Future Prospects of Glass Science and Technology. Proceedings of the Norbert Kreidl Symposium, Triesenberg, 3-8 July 1994, 63-78.

[10] Gupta, N., Balrajsinghbrar and Eyassuwoldesenbet (2001) Effect of Filler Addition on the Compressive and Impact Properties of Glass Fibre Reinforced Epoxy. Bulletin of Materials Science, 24, 219-223. https://doi.org/10.1007/BF02710105

[11] Pardo, S., Baptiste, D. and Decobert, D. (2002) Tensile Dynamic Behaviour of a Quasi-Unidirectional E-Glass/Polyester Composite. Composites Science and Technology, 62, 579-584. https://doi.org/10.1016/S0266-3538(01)00152-X

[12] Mamalis, A., Manolakos, D., Demosthenous, G. and Ioannidis, M. (1996) Energy Absorption Capability of Fibre Glass Composite Square Frusta Subjected to Static and Dynamic Axial Collapse. Thin- Walled Structures, 25, 269-295. https://doi.org/10.1016/0263-8231(95)00057-7

[13] Hajiaghamar, M., Seidi, M., Fergson, J.R. and Caccese, V. (2015) Measurement of Head Impact Due to Standing Fall in Adults Using Anthropometric Test Dummies. Annals of Biomedical Engineering, 43, 2143-2152. https://doi.org/10.1007/s10439-015-1255-1

[14] Adekomaya, O. and Adama, K. (2017) Glass-Fibre Reinforced Composites: The Effect of Fibre Loading and Orientation on Tensile and Impact Strength. Nigerian 
Journal of Technology (NIJOTECH), 36, 782-787.

[15] Wallenberger, F.T. (2010) Commercial and Experimental Glass Fibres. In: Wallenberger, F.T. and Bingham, P.A., Eds., Fibreglass and Glass Technology, Springer US, Berlin, 3-90. https://doi.org/10.1007/978-1-4419-0736-3 1

[16] El-wazery, M.S., EL-Elamy, M.I. and Zoalfakar, S. (2017) Mechanical Properties of Glass Fibre Reinforced Polyester Composites. International Journal of Applied Science and Engineering, 14, 121-131.

[17] Aramide, F.O., Atanda, P.O. and Olorunniwo, O.E. (2012) Properties of a Polyester Fibre Glass Composite. International Journal of Composite Materials, 2, 147-151. https://doi.org/10.5923/j.cmaterials.20120206.06

[18] Kumar, M.S., Raju, N.M.S., Sampath, P.S. and Vivek, U. (2015) Tribological Analysis of Nano Clay/Epoxy/Glass Fibre by Using Taguchi's Technique. Materials \& Design, 70, 1-9. https://doi.org/10.1016/j.matdes.2014.12.033

[19] Cochran and Cox (1957) Randomized Complete Block Designs, Adapted from Experimental Designs. 2nd Edition, John Wiley \& Sons, Inc., Hoboken. 